\title{
O CRÍTICO E O CRONISTA NA INTERFACE DE UM GÊNERO "MENOR"
}

\section{THE CRITICAL AND THE CRONIST IN THE INTERFACE OF A LITERACY GENRE "DISCREDITED"}

\author{
Maria de Lourdes Patrini Charlon ${ }^{1}$ \\ Mácio Alves de Medeiros ${ }^{2}$
}

\begin{abstract}
RESUMO
O presente trabalho discute a presença do crítico literário Antonio Candido nos arquivos que compõem um acervo de crônicas e textos diversos publicados pelo escritor capixaba Rubem Braga. Essa discussão foi gerada a partir da identificação da presença desse crítico brasileiro em textos escritos por Rubem Braga, na análise feita a respeito das crônicas escritas por este e, também, em situações variadas envolvendo a literatura e outros escritores. Nesse processo, as palavras do crítico literário auxiliam a compreensão do gênero crônica dentro do próprio espaço em que os textos se apresentam para o leitor e, ademais, permitem ao pesquisador confirmar, pela autoridade consolidada de Antonio Candido, a importância da crônica para a literatura e a cultura brasileira.
\end{abstract}

PALAVRAS-CHAVE: Rubem Braga; Antonio Candido; Crônica; Crítica literária.

\begin{abstract}
The present work discusses the presence of the literary critic Antonio Candido in the archives that compose a collection of chronicles and diverse texts published by the 'capixaba' writer Rubem Braga. This discussion was generated from the identification of the presence of this Brazilian critic in texts written by Rubem Braga, in the analysis made on the chronicles written by him and also in various situations involving literature and other national writers. In this process, the words of the literary critic help the understanding of the chronic genre within the very space in which the texts present themselves to the reader and, in addition, allow the researcher to confirm, by the consolidated authority of Antonio Candido, the importance of the chronicle for literature and Brazilian culture.
\end{abstract}

KEYWORDS: Rubem Braga; Antonio Candido; Chronic; Literacy criticism.

\section{INTRODUÇÃO}

A visão de Antonio Candido sobre a literatura brasileira perpassa qualquer teorização a respeito da crônica, afinal esse modelo de fazer literário é entendido por ele não como gênero menor, mas seguramente como sólido e fecundo terreno no qual se pode vislumbrar uma interface particular entre realidade jornalística e conteúdo ficcional.

Num projeto que tenciona organizar uma provável relação de obras completas do cronista Rubem Braga, os artigos de natureza diversa trazem um pouco da trajetória desse

1 Doutora em Antropologia Social pela École des Hautes Études en Sciences Sociales, de Paris, pesquisadora/bolsista do CNPq. E-mail: patrini.ml@gmail.com

2 Doutor em Literatura Comparada pela Universidade Federal do Rio Grande do Norte, professor de língua portuguesa da rede estadual e da municipal de educação do Rio Grande do Norte. E-mail: marcio.amedeiros@yahoo.com.br 
reconhecido crítico, ensaísta e teórico da literatura. Isso ocorre tanto através de textos do Braga ou de textos pertencentes a outros críticos e escritores com discursos presentes no arquivo do cronista maior da nossa literatura. Contudo, um dos objetivos do presente trabalho é privilegiar os arquivos que trazem a marca do crítico brasileiro, voltados ao debate sobre a crônica e associados, de algum modo, ao processo constitutivo desse gênero, ao longo do século XX. Da mesma forma, torna-se importante destacar como a presença de Antonio Candido se manifesta no discurso de Rubem Braga. Essa presença se manifesta por meio dos excertos encontrados durante as investidas realizadas sobre o arquivo relativo à obra do cronista.

Como se deve imaginar, nesses textos críticos o discurso de Antonio Candido se entrelaça às questões inerentes ao trabalho de composição, análise e interpretação do arquivo braguiano. Essas questões, inicialmente, visam à identificação da produção dos textos do cronista em suas variadas versões, publicadas ao longo de décadas de contato com o jornal, e na companhia do exercício jornalístico profícuo. No entanto, por outro lado, tais questões também remetem a indagações relativas ao próprio conjunto da produção deixada por Rubem Braga, e cuja tentativa de juntar todos os fios dos milhares de textos e versões constitui a aceitação de entrar num labirinto consistente, contudo desafiador. Para tanto, uma das variantes de lidar com o arsenal artístico do cronista exige a compreensão e a discussão relativa a terminologias como: inventário, arquivo e fundo de arquivo, destacadas, dentre outros, por Jacques Derrida (1995) e Arlette Farge (2009).

De outra forma, Antonio Candido aparece não apenas como apreciador do fazer literário nacional, como crítico literário, mas, por vezes, como personagem da escrita de Rubem Braga, numa alusão verdadeira deste, durante o seu fazer diário, à importância do crítico da literatura e, provavelmente daquele que melhor teorizou a respeito do gênero literário pelo qual o jornalistaícone de Cachoeiro de Itapemirim ganhou notoriedade.

\section{Os primórdios da pesquisa}

Desde 2008 estamos envolvidos num projeto de pesquisa que tem por objetivo maior a publicação da obra completa de um dos maiores expoentes da crônica literária brasileira no século XX. A etapa inicial constituiu-se da digitalização dos materiais oriundos de dezenas de periódicos de todo o país, espaço por onde transitou, através da escrita jornalística e ficcional, a experiência cotidiana de Rubem Braga. $\mathrm{Na}$ fase seguinte, deu-se a organização do acervo desses materiais, realizados sob os cuidados do pesquisador-coordenador do projeto, e de seus auxiliares, levando-se em conta os pressupostos teórico-metodológicos oriundos dos projetos relacionados à pesquisa e que, aos poucos, foram sendo incluídos para sustentar o processo analítico. A partir dessa fase já foram vislumbrados alguns resultados preliminares os quais foram divulgados em momentos como este.

Desse modo, ao longo desses anos nos quais a pesquisa ganhou dimensão, e foi apoiada pelo $\mathrm{CNPq}$, recorreu-se a um laborioso trabalho de constituição do corpus. A partir disso, e em função da grandiosidade do acervo, tem-se estabelecido uma organização que leva em conta a divisão por periódicos (jornais, revistas, semanários etc.), o ano da publicação, bem como a identificação dos manuscritos. A partir daí, considerando neste momento apenas as crônicas, a pesquisa traça um perfil dos diversos textos desse gênero publicados por Rubem Braga ao longo de sua trajetória profissional e pessoal para, em seguida, atuar concomitantemente na descrição dos dados quantitativos e na análise dos aspectos qualitativos do acervo do cronista.

Durante mais de meio século Rubem Braga fez do exercício profissional de jornalista um trampolim para a atividade de cronista. E, através da escrita diária em diversos periódicos, sua marca pessoal estabeleceu um forte e legítimo laço entre o jornalismo e a literatura. Se o primeiro é caracterizado pela necessidade constante de novos dados, fatos e informações que atestam a existência de uma sociedade em toda a sua complexidade, a segunda, a literatura, rejeita o estatuto 
da efemeridade, pois edifica pela verossimilhança a experiência humana. Na observação disso, Rubem Braga foi exímio confidente da arte literária e da cultura brasileira. O cronista promoveu a efervescência de um gênero que ainda busca a sua legitimidade no campo literário, e que talvez já a tenha encontrado, restando apenas à crítica não tratá-la como um gênero menor senão distinto dos demais.

Preocupado mais em juntar a observação da experiência humana com a reflexão imanente de escritor-jornalista, ou jornalista-escritor, Rubem Braga disponibilizou seus textos para mais de uma centena de periódicos, notadamente nos estados do Sudeste e do Sul, mas também marcou presença em estados das demais regiões do Brasil. Desse modo, muitos foram os arquivos nos quais a escrita braguiana se instalou. Entretanto, como todo ato de criação literária, inúmeras devem ter sido as escrituras e reescrituras realizadas pelo cronista antes de uma decisão tácita sobre a publicação de determinado texto. Mais que isso, muitas são as crônicas publicadas por Rubem Braga em mais de um periódico ou por mais de uma vez num mesmo periódico, todavia, inúmeras delas trazem em si modificações textuais desde o título, simbolizando assim um processo contínuo do escritor no aprimoramento (em sentido lato) de sua obra? Essa constatação se fez perceber na pesquisa realizada junto à Fundação Casa de Rui Barbosa, especialmente. Imaginemos, portanto, por outro, como seriam as estruturas dessas crônicas em suas formas manuscritas, incluindo-se nisso os modelos datilografados? Essas e outras questões recorrentes da problemática mais ampla que envolve o tratamento com o arquivo do cronista.

Assim, em face ao volumoso número de textos produzidos por Rubem Braga, e, na ausência do inventário de sua obra completa, o pesquisador se debruça sobre os arquivos e documentos disponibilizados pela família do cronista. Com isso, num trabalho incluindo pesquisa, digitalização e organização surgiram artigos de outros escritores e críticos, dentre eles Antonio Candido, os quais tratam do gênero adotado por Rubem Braga ao longo de sua carreira jornalística. Afinal, como se sabe, uma característica comum no trabalho deste jornalista-cronista (ou cronista-jornalista) foi a escrita e a reescrita de uma mesma crônica já publicada em determinado periódico. Por isso, considerando o tratamento contínuo empreendido por ele a muitas de suas narrativas acaba-se encontrando uma versão derradeira. Esta, vulnerável, todavia, pois se tempo de vida ainda houvesse para o cronista voltar a ela, possivelmente, republicá-la-ia com nova forma, restando, contudo, apenas, ou ainda, uma imagem esmaecida do conteúdo ou do enigma estabelecido pelo autor nas versões anteriores. Tal procedimento, testemunha e legitima a existência de outra versão ou de várias versões decorrentes e anteriores às mais recentes.

\section{O fundo Rubem Braga}

O arquivo é feito de acumulação e fazer do arquivo seu campo empírico e de interpretação é estar diante de uma fonte de informações inesgotável. É igualmente compartilhar de uma experiência singular. A definição de Arlette Farge (1989), historiadora e renomada pesquisadora dos arquivos judiciários na França, leva-nos a refletir de forma mais comprometida sobre arquivo.

A estudiosa faz um alerta enfatizando que

[...] $\mathrm{O}$ arquivo não se parece nem com os textos, nem com os documentos impressos, nem com os "relatos", nem com as correspondências, nem com os diários, e nem mesmo com as autobiografias. [...] O arquivo é uma brecha no tecido dos dias, a visão retraída de um fato inesperado. [...] $\mathrm{O}$ arquivo age como um desnudamento; encolhidos em algumas linhas, aparecem não apenas o inacessível como também o vivo. [...] Sem dúvida, a descoberta do arquivo é 
um maná que se oferece, justificando plenamente seu nome: fonte (FARGE, 2009, p. 11-15).

Ela explica, em seguida, que o arquivo se subdivide em fundos, este é o nome dado ao conjunto de documentos sejam eles homogêneos ou simplesmente um conjunto de materiais reunidos, doados por um particular que detinha sua propriedade. Os fundos de arquivo (fonds d'archives) compõem-se de conjuntos de documentos, de formas e suportes variados, eles podem ser públicos ou privados.

À definição acima acrescentaremos a de Paul Ricoeur, estudioso que desenvolve considerações importantes sobre esse assunto no livro: Temps et récit - 3. Le temps raconté: "Os arquivos são os fundos" (1983, p. 197) e a noção de documento está contida na definição de arquivos, enquanto a noção de rastro está contida na de depósito. A noção de documento abordada etmológicamente significa ensinamento, informação, transição, mas contém igualmente a acepção de apoio, de garantia - de prova material (evidence), relação que é feita de uma sequência de acontecimentos.

Em seu estudo, Paul Ricoeur adota a acepção da Enciclopédia Universalis de que "os arquivos são constituídos pelo conjunto de documentos que resultam da atividade de uma instituição ou de uma pessoa física ou moral"' (1983, p.196).

Conforme o filósofo apresenta em seu livro, acima citado, no tópico 3, do II. Capítulo das acepções das Enciclopédias Universalis e Britannica, podemos extrair três características: 1- a noção de documento: os arquivos são um conjunto; um corpo organizado, de documentos, de registros; em seguida a relação a uma instituição: os arquivos são compreendidos (pertencentes) dentro de um caso, resultado (résulter) da atividade institucional ou profissional; 2- eles são ditos, produzidos ou recebidos pela entidade cujos documentos são os arquivos; enfim, 3- os arquivos têm por objetivo conservar, preservar os documentos produzidos pela instituição indicada (ou seu equivalente jurídico). É importante ressaltar que, conforme precisa a Enciclopédia Universalis, os arquivos, ao contrário das bibliotecas, constituídas por documentos reunidos, "são apenas documentos conservados". A Enciclopédia Britannica por sua vez e num sentido bem próximo ao anterior, afirma que “a conservação faz dos arquivos 'um depósito autorizado' pelas estipulações que completam a definição dos objetivos da instituição considerada" (1983, p.197).

Em seu carácter institucional, os arquivos constituem os fundos documentários de uma instituição. Atualmente, a ênfase dada à noção de documento é sobre a função de apoio, de garantia "apporté à une histoire, un récit, un débat" (1983, p.213), constituindo uma prova material, o que em inglês é chamado "evidence", de la relation faite d'un cours d'événements" (1983, p.213-214). A noção de documento pode ser conduzida por diversos níveis de aprofundamento. Em todos os casos, o importante é que o pesquisador saiba interrogar "seus vestígios e colocá-los em questão" (1983, p.197). Uma escolha razoável de questões servirá de guia ao pesquisador, pois a caça aos documentos não cessa de anexar (1983, p.214) zonas de informação.

\section{A presença de Antonio Candido no arquivo Rubem Braga}

O objetivo central, ao nos referirmos à presença desse crítico literário no terreno de ação preferido por Rubem Braga, é mostrar a boa interferência de Antonio Candido ao longo de um percurso de produção literária do cronista, trajetória que iniciada por volta de 1952 e que se prolonga até 1989.

De qual fonte falamos aqui? Referimos-nos ao arquivo Rubem Braga, depositado no Arquivo Museu de Literatura da Fundação Casa de Rui Barbosa, no Rio de Janeiro. O trabalho com um arquivo exige conhecimento de suas condições materiais, suas propriedades estruturais. Nosso primeiro encontro com o arquivo deve ser sempre consagrado ao exame do seu depósito. 
Outra ressalva importante: trabalhar com um arquivo não significa simplesmente dominar o passado ou a memória de uma obra. Além do mistério que envolve os fundos de arquivo, mistério de criação, a gênese, os inéditos e o secreto parecem, igualmente, habitar o mundo dos arquivos. Dito isto de forma bem rasteira, a intenção é chamar a atenção para a necessidade de, ao se trabalhar com um arquivo, torná-lo vivo, manter sempre os olhos voltados para o futuro.

Desse modo, e conforme preconiza a crítica genética, para compreendermos as intenções do autor faz-se necessário encontrar a forma original de sua obra, o seu embrião. Daí até o texto final existe um percurso que a teoria genética pretende acompanhar por meio da análise da forma computada como manuscrita. Evidentemente, não se trata de aplicar uma analise filológica nem tampouco da história literária, pois a perspectiva adotada, e defendida pelos geneticistas, embora muitos deles filólogos, "não é o texto, mas a textualidade complexa da obra em construção" (GRÉSILON, 2007, p. 277).

No caso de Rubem Braga, a aplicação das reflexões da crítica genética recai sobre os textos de crônicas escritas à mão, ou mais propriamente os textos de crônicas datilografadas com ou sem correções feitas a lápis. O debruçar-se sobre os materiais produzidos pelo cronista e que constituem um aglomerado ainda movediço de documentos jornalísticos e documentos literários, representa, sobretudo, a necessidade de vivenciar as experiências particulares com o arquivo, isto é, um mergulho na desordem em que o enigmático se revela. Para Farge (2009, p. 12-13),

\begin{abstract}
Desconcertante e colossal, o arquivo atrai mesmo assim. Abre-se brutalmente para um mundo desconhecido em que os rejeitados, os miseráveis e os bandidos fazem a sua parte em uma sociedade vigorosa e instável. Sua leitura provoca de imediato um efeito de real que nenhum impresso, por mais original que seja, pode suscitar. O impresso é um texto dirigido intencionalmente ao público. É organizado para ser lido e compreendido por um grande número de pessoas; [...]. Nada a ver com o arquivo; vestígio bruto de vidas que não pediam absolutamente para ser contadas dessa maneira [...].
\end{abstract}

Neste momento, mergulhamos em parte desse arquivo, trilhando um viés particular, aquele no qual reluz a escrita ou a figura mesmo de Antonio Candido. Inserido na maioria das vezes, claro, no contexto do debate acerca do gênero crônica, remetemo-nos a uma questão primordial: como explicar, portanto, que um texto de crônica se reconstrói e se reconfigura no processo de se tornar público, isto é, nas várias edições que se sucedem à primeira? Isso mesmo se levado em consideração a interface entre jornal e livro, ou entre estes e um manuscrito, como espaço de publicação, e, ainda, se considerada também uma intenção deliberada do cronista em tornar uma forma narrativa (neste caso uma crônica) suscetível de metamorfosear-se em outra, neste caso em conto, por exemplo. Em duas das imagens do corpus aqui demonstrado leva em conta essas transformações e sinaliza, preliminarmente, para alguns aspectos inerentes a essa constatação.

Rubem Braga passou a vida escrevendo sobre aquilo que via na sua experiência com o cotidiano e sua marca autoral se fazia pública a cada dia. Por isso, fossem naqueles espaços onde exerceu sua atividade funcional ou naqueles que reclamavam sua escrita diária, visando o deleite dos leitores, a presença do cronista maior da literatura brasileira se manifestava em textos carregados de lirismo, no dizer de Antonio Candido e José Aderaldo Castelo (1985), que o consideravam também o mais poeta dos prosadores do Modernismo, por ter sido o primeiro a elevar a crônica ao nível da mais alta categoria literária, colocando-a acima dos seus compromissos frequentes com o contingente ou o momentâneo. Por sua vez, o propósito de nossa pesquisa é o de mapear, cronologicamente, o conjunto da produção de Rubem Braga como escritor e jornalista, com vistas à organização e preparação da obra completa do autor. Este fazer de todo dia levou-nos a uma descoberta: a presença de Antonio Candido e de seu trabalho de crítico nos escritos e publicações de Rubem Braga e de terceiros. 
Traçamos aqui um percurso de ocorrências da inserção de crítico brasileiro de modo ora aleatório, ora cronológico, ora temático. Todavia, no conjunto de imagens usadas a partir do fundo Rubem Braga, a primeira das aparições de Candido ocorre no texto "O Mundo" dos Escritores, seguido do título da seção "Os cadernos de cultura", de autoria de O Redator LITERÁRIO, da revista, em matéria publicada em $O$ Mundo, RJ, 01/07/1952. Neste documento temos a presença de Candido entre os velhos conhecidos, e já publicados na revista, na referida seção. A ele juntam-se Clarice Lispector, Otto Maria Carpeaux, Álvaro Lins, entre outros. Rubem Braga aparece como futura publicação com: Três Primitivos e Crônicas do vento e do mar.

Ainda em 1952, (11/07, p. 15) na revista Comício, cujos diretores eram Joel Silveira, Rafael Correa de Oliveira e Rubem Braga, Antonio Candido aparece como componente da comissão A (Cultura), do III Congresso Paulista de Escritores. O último tinha sido realizado em 1945. O texto é de Luís Martins e fizeram parte da mesma comissão: Sérgio Buarque de Holanda, Décio de Almeida Prado, entre outros oriundos de cidades do interior paulista. O texto se estende pelas páginas 14, 15 e 27 da revista. Em outra publicação da revista Comício, 08/08/1952, p. 26, sem indicação de autor, o destaque fica por conta do texto "Congressos, Urbanismo e Arquitetura no IV centenário". Nessa ocasião, Antonio Candido faz parte da Comissão do IV Centenário pela Consultoria Técnica do Serviço dos Congressos em Geral. Vale citar algumas personalidades importantes, pois a comissão é composta por muitos nomes, entre eles: Agostinho Alvim, Alcides Vidigal, Décio de Almeida Prado, Fernando Azevedo, Miguel Reali, Guilherme de Almeida, Sérgio Buarque de Holanda, Candido Mota Filho e Plínio Ayrosa.

A terceira presença de Antonio Candido ocorre em Manchete, 27/11/1954, p. 59, nesse documento o texto é de autoria de Rubem Braga e se inicia na página 58. O título do artigo é "João Cabral, poeta" e destaca o prêmio conquistado por esse escritor pernambucano. O concurso tem por nome "Cem contos do IV Centenário", em 1953. Durante dois meses - janeiro e fevereiro de 1953 - João Cabral de Melo Neto escreve um longo poema intitulado "Rio" ou "Relação da viagem que faz o Capibaribe de sua nascente à cidade do Recife". Isto para se submeter a um rigoroso júri, e em anonimato. Como jurado desse concurso está novamente Antonio Candido, desta vez compondo a comissão com Paulo Mendes Campos e Carlos Drummond de Andrade. O louvor a João Cabral de Melo Neto irá aparecer mais tarde na edição de Isto é, de $02 / 12 / 87$, numa reportagem incompleta, pois falta a página inicial, assinada por Humberto Werneck. Na página 35 (vai até a 37) aparecem Antonio Candido, cuja imagem está na parte superior, e Rubem Braga, na parte inferior, ambos destacando o valor estético da literatura produzida pelo escritor pernambucano.

Em O Estado de São Paulo, publicado em 03/01/1956, tem-se uma crônica sob o título "Apelidos", da seção A Sociedade e de autoria de L.M, provavelmente as iniciais do cronista Luís Martins. O texto da crônica mostra a presença tanto de Antonio Candido quanto de Rubem Braga, afinal relata a criação do grupo paulista da revista de cultura "Clima". Essa crônica, de certa forma, mostra o início da amizade entre o autor dessa crônica, Rubem Braga, e Antonio Candido, além dos outros intelectuais citados por L.M.: Paulo Emilio Salles Gomes, Lourival Gomes Machado, Rui Coelho, Décio de Almeida Prado e outros.

Antonio Candido aparece como fecundo intelectual responsável, juntamente com tantos outros, pela publicação de obras de cunho crítico no ano de 1956. Seu trabalho de análise crítica levava o título de Fição e confissão e se referia à obra de Graciliano Ramos. Esse documento foi publicado em Correio do Povo (Recife - PE) em 13/01/1957, numa publicação intitulada "Visão Intelectual de 1956" e de autoria de Augusto Bourdoux, na seção Vida dos Livros. Nesse texto, o destaque para as publicações da Livraria José Olympio, Rubem Braga e Candido figuram na mesma lista. O primeiro com $A$ Borboleta Amarela, livro de crônicas e a tradução de Terra dos Homens.

Na sequência, em Folha da Manhã de São Paulo, em 20/07/1957, e na seção Movimento Literário, sob a responsabilidade de Maria de Lourdes Teixeira, a publicação "Os cadernos de 
cultura" traz o histórico das publicações: cadernos de cultura, destacando os 105 volumes já publicados, todos de excelente qualidade segundo autora do artigo. Com destaque para os autores do Rio de Janeiro, Antonio Candido é citado como autor de Monte Cristo, ou da vingança.

Do Jornal do Brasil, 09/10/1960, tem-se na seção Vida Literária, um artigo de

Mauritônia Meira o qual traz uma lista de publicações a serem lançadas por editoras brasileiras depois das eleições de 1960. Como sempre, focalizando o trabalho da Editora José Olympio, aparece a obra Civilização e cultura, de Luís da Câmara Cascudo e, de Antonio Candido, merece destaque a sua colaboração na organização da obra História Geral da Cultura Brasileira, organizada por Sérgio Buarque de Holanda.

Do jornal Última Hora, Rio de Janeiro, 24/01/1969, de autoria de Rubem Braga, o crítico Antonio Candido aparece novamente como membro de júri, mencionado pela nota "Ganhe 15 mil novos", na seção Vamos abrir os livros. Trata-se de um concurso de contos em Curitiba. Além do crítico, participam da comissão julgadora, de alto gabarito, entre outros nomes, Fausto Cunha e Temistócles Linhares. Em outra publicação desse mesmo jornal, em 05/05/1969, uma nota - "Graciliano de roupa nova" - chama a atenção para a publicação das obras completas do escritor Graciliano Ramos, num trabalho realizado pela editora Martins. A presença de Antonio Candido é marcada no prefácio ao volume de São Bernardo, enquanto Alexandre e outros heróis aparece prefaciado por José Geraldo Vieira. A coleção, caracterizada por volumes de capa verde, foi publicada dezesseis anos depois da morte do escritor alagoano.

$\mathrm{Na}$ Revista Nacional, Rubem Braga tinha uma seção com o seu nome e, nela, aparecia sempre uma crônica, de sua autoria, e uma seção - A poesia é necessária - contendo um poema de uma obra a ser comentada na sequência da seção. Nesta edição figura o livro de poesias intitulado Em nome da vida, escrito por Moacyr Félix, publicado pela Civilização Brasileira, em 1981. Ao final de um comentário sobre a obra, Rubem Braga anota: "Antonio Candido sente nesses versos a indignação galopada dos poetas românticos", referência direta ao trabalho criterioso e, aqui, à presença indireta, do crítico de nossa literatura. Ainda nessa linha do apreço à obra de outrem, no periódico Visão, de 15/04/66, o elogiado da vez é outro poeta pernambucano. Com o título "Manuel, Bandeira de nossa poesia", o cronista destaca as palavras de Antonio Candido, para quem Manuel Bandeira era o grande clássico da nossa poesia contemporânea. $\mathrm{O}$ texto se prolonga com elogios ao poeta vindos de tantos outros colegas de ofício e demais personalidades de discurso patenteado.

$\mathrm{Na}$ edição do Diário de Pernambuco, de 08/03/1985, na seção Panorama Literário, num artigo - "A volta do cigano", publicado por Sebastião Vila Nova, este, faz referência a Recado de Primavera, em razão de uma publicação recente da editora Record, em 1984. Nessa crônica, o jornalista destaca a comparação feita por Rubem Braga em uma crônica: "há homens que são escritores e fazem livros que são verdadeiras casas, e ficam". Ele confronta esse trecho com outro: "o cronista de jornal é como o cigano que toda noite arma a sua tenda e pela manhã a desmancha e vai".

Com isso o escritor insere o cronista-jornalista capixada nas duas condições, pois publicava diariamente em jornal, mas também publicou em livros, remetendo à recente publicação de uma de suas obras. Nesse caso, Antonio Candido entra como destaque na teorização do gênero, porque, segundo o crítico, a crônica, "sob vários aspectos é um gênero brasileiro, pela naturalidade com que se aclimatou aqui e a originalidade com que aqui se desenvolveu". Esta, como a citação anterior, estão inseridas na crônica do jornalista do Diário, sem indicação referencial. Descobrimos, entretanto, que a citação de Rubem Braga está na crônica "Manifesto" da obra A Borboleta Amarela. Já a citação de Antonio Candido é do seu célebre ensaio $A$ vida ao rés do chão.

Este mesmo contexto envolvendo Braga na condição de cronista e Antonio Candido na posição de teórico do gênero figura o arquivo de Jornal do Comercio, de 15/03/89, num artigo que ocupa uma página inteira do jornal e é assinado pelo jornalista e escritor Danilo Gomes. Este 
artigo, no arquivo Rubem Braga, integra a subpasta nomeada de "As boas coisas da vida", de um conjunto de Dossiês sobre a obra desse cronista.

Seguindo a linha da presença de Antonio Candido como teórico, a Folha de São Paulo, de 05/10/85, na seção Folha Ilustrada, no. 49 (em dois arquivos), traz também um artigo do jornalista Leão Serva, e pequenos ensaios do professor Davi Arigucci Júnior, acerca da crônica e de seu representante maior, no Brasil. Esses dois não esquecem, entretanto, de referir-se a Antonio Candido e às suas colaborações reflexivas acerca desse gênero "menor" que, por tal aspecto, assegura Candido, ele se permite está perto de nós, os leitores, ou os humanos do mundo real?

Fugindo, não da crítica literária, mas saindo do campo da crônica, o Suplemento Literário, $n^{\circ}$. 816, de 22/05/82, do Diário de Minas, publica um artigo intitulado "Literatura e Integralismo: um percurso ideológico", assinado por Antonio Arnoni Prado. Em seu texto, como o próprio nome sugere, a citação a Antonio Candido é feita para sustentar a noção criada, no Brasil, a partir da República, segundo a qual foi necessário um redescobrimento calcado na "consciência amena de atraso". A esta premissa, segundo Candido, soma-se a intenção de fazer reviver a ideologia libertária do Romantismo que, para o jornalista, deve ser apoiada agora no mito do novo homem do Novo Mundo. Assim, seríamos o símbolo renovado da cultura e da tradição europeia no espaço promissor da pátria redescoberta, garante o jornalista, baseado no pensamento do crítico literário.

\section{A presença da crítica de Antonio Candido na criação estética de Rubem Braga}

O objetivo deste texto está sendo mostrar a presença do crítico e escritor Antonio Candido na obra de Rubem Braga. De acordo com a busca empreendida no arquivo da obra de Rubem Braga, depositado no Arquivo Museu da Literatura Brasileira (AMLB) e na Fundação Casa de Rui Barbosa (FCRB), no Rio de Janeiro, foram selecionadas 24 imagens/textos, nos quais Antonio Candido, o crítico e escritor, está presente.

Estas imagens são recortes de periódicos que foram publicados na imprensa brasileira. As publicações dos tais recortes atravessaram décadas. São recortes de natureza diversa: notas, reportagens, crônicas, etc. Entre a diversidade encontrada, há duas crônicas, dentre as 24 imagens, que merecem ser apresentadas com alguns dados e informações suplementares. Afinal, apontar somente a presença de Antonio Candido no texto do cronista parece insuficiente, dada a importância do crítico na diversidade de textos do escritor. Afinal, não se trata apenas de uma presença, mas de uma escolha, de um vínculo que engendra papéis e significados ao narrar do cronista.

A primeira das duas crônicas é intitulada "A grande mulher de aeroporto internacional" (1981). É uma crônica muito importante porque Antonio Candido aparece como personagem. Ela foi publicada cinco vezes com três títulos diferentes: "A grande mulher do Aeroporto Internacional”: L'Officiel (fev. e março de 1979); Revista Nacional, n¹24, Revista Fluminense (dez. 1981); "Não sei se ainda há mulheres assim" (Correio do Povo, 04/07/1982) e "A grande internacional", em (Recado de Primavera, 1984).

Nestas crônicas, como em tantas outras, comprova-se a habilidade do cronista para imprimir em seu texto, sempre em meio a tantos assuntos, fatos/acontecimentos que interagem ao longo do seu contar, apesar de, por tantas vezes, nada possuírem de comum entre eles. Esta maestria do cronista requer atenção. Seu jeito de manejar certos assuntos, com graça e com um toque de humor singelo, se mistura à dose certa de ironia inteligente, componente assíduo em sua narrativa. Essa estratégia, por vezes, deixa o leitor desconcertado e perplexo, porém maravilhado.

Nisso Rubem Braga se esmera ao misturar o sumo das experiências que preenchem o cotidiano, a beleza e a força do imponderável. Na crônica: "A grande mulher de aeroporto internacional" como em tantas outras, o leitor acompanha o narrador num passeio pela narrativa 
de histórias, de fatos e de detalhes que se intercalam, se misturam e se encaixam sem cerimônia, finalizando num alinhavo seguro.

Sem receio, o cronista expõe com doçura a beleza de uma "inverossímil visão" acerca de uma "matinalidade inesperada". São suas fantásticas mulheres, suas deusas. Mitos que povoam seus casos. Donas de olhos "inevitavelmente azuis" ou verdes como "olhos de piscina", olhos de azul límpido (BA p.149) e "olhos quase verdes" (B.A., p. 89). Eles consentem toda sorte de impacto e de beleza, enquanto o cronista desce, sem avisar e, em instantes, estando já "ao rês-dochão" (CANDIDO, 2003, p. 91), cede passagem às experiências de todo dia, tonalidades raras, as quais se prolongam no texto, pelas mãos ágeis de um criador sem par.

Como foi mencionado, desta crônica em estudo, há cinco publicações. Nelas estão presentes Antonio Candido, Gilda de Melo e Souza, Mário de Andrade entre outros. Rubem Braga identifica-os como atuantes da revista "Clima". Como parentes entre si, ou quem sabe primo de um suposto comandante, da Varig? Talvez da Panair.

Assim, nas cinco versões, o cronista/narrador prepara os espaços, que, no ato de contar, vão se constituindo. Neles, acontecimentos irão persistir. O tempo se faz cúmplice do narrador, apagando fronteiras, ora impondo a brevidade ora o prolongamento de um tempo imensurável. Alguns, subitamente ganham solenidade, e, eis que o imponderável acontece: "[...] apenas um instante, mas me feriu os olhos de beleza para sempre". Recordação, sonho, quase lenda. Num sincretismo. Quase uma pré-história que se liga a outro momento compondo nova história. $\mathrm{O}$ narrador se perde nos dados concretos, eles não parecem ter de fato importância, a experiência do vivido permanece. Ele busca na trégua o sopro e se recorda ao procurar soluções para situar o espaço.

Do mesmo modo, tal como em busca de alívio ou superação, ele se lembra da conversa com o comandante que, diante da imprecisão, volta a assumir as rédeas dos acontecimentos e tal qual a voz de um narrador oral, segue a trocar fatos com seu ouvinte, traçar linhas de parentesco de um determinado comandante, primo? Quem sabe? De quem? E o jeito descompromissado do gênero crônica parece trazer narrador e leitor para acontecimentos mais corriqueiros, frutos do dia a dia.

Desta forma, entram para a narrativa o crítico Antonio Candido e a escritora Gilda de Melo e Souza, num cenário marcado pelo encontro do casal na Confeitaria Vienense, ambos a tomarem leite maltado. Estes, portanto, representantes do real, do palpável. Afinal, não se pode viver de tantas incertezas. O narrador dessa crônica, por seu lado, explica para o seu leitor quem são estas pessoas, onde se encontram, quais são seus hábitos, num movimento oscilante da dúvida, porém contando fatos banais.

Contudo, o narrador precisa se segurar. Não pode se deixar engolir. Abandona e volta lentamente tentando acertar o espaço, sem controlar os limites geográficos onde tudo se passou. Confirma um fato: ambos "faziam parte de uma roda que tinha Paulo Emílio, pessoal de uma revistinha (nas demais versões: revista) chamada "Clima". Crítica? Talvez? O tempo passou desde a primeira publicação da crônica, em 1979. Assim, entre outros participantes importantes, mas todos de carne e osso, localizáveis no mundo dos homens; volta-se para si e enaltece seu prazer em tomar uma "Original" com seus amigos. Num tom de conversa afiada, próprio de quem joga conversa fora com os amigos, dirige-se para o leitor: [aliás a Gilda era também (?) sobrinha de Mário de Andrade - será que o comandante era parente de Mário?] Descontração, conversa emendada.

Aparentes registros, as informações se mesclam num tom de ironia, numa busca de simplicidade que jamais pode ser confundida com uma atitude de evasão. Rapidamente o narrador arremessa outros fios e [“o que interessa é que num aeroporto de língua predominantemente alemã"] aviões aterrissam e subitamente ["surgiu aquela mulher"] superando os acontecimentos rumo a uma dimensão estendida de um de seus "mitos recorrentes" (CHAVES, 1978, p. 99): a mulher. [“São muitos os vultos femininos, mas, integrando-os a todos 
[...] a crônica fixa literariamente uma só mulher - verdadeira síntese do transitório...”] ["Por quê? A sua qualidade de transiente (ela jamais está embarcando ou chegando, é sempre passageira em trânsito) lhe dá um leve ar de fadiga e também de excitação.'] (Braga, 1978).

Num movimento, a crônica volta a recorrer à "insuficiência do real" (CHAVES, 1978, p. 101): A iluminação da ["Mulher madura, não. Digamos: de vez"] (BRAGA, 1979) ou de-vez. Diante da questão, faz apelo ao mestre e amigo Aurélio Buarque de Holanda. E a hora é a de documentar e falar das ferramentas necessárias ao ofício do cronista. Discute-se em um parágrafo a língua e a quase submissão que ela impõe ao escritor, vítima de sua estrutura e de suas normas. Mas, em seguida, surge uma nova aparição: "[...] de súbito surgiu aquela mulher. Linda! Tão linda assim, só mesmo sendo mulher de aeroporto internacional [...]".

As diversas versões da crônica aqui apresentada possuem diferenças textuais, a pesquisa junto ao arquivo de Rubem Braga aponta para uma característica do cronista. Característica ímpar em se tratando de cronistas. Rubem Braga revia seus textos, mesmo depois de muito tempo. São muitas as crônicas já publicadas que sofreram correções, cortes do cronista. O pesquisador que convive com a obra do cronista conhece a profusão de crônicas que se espalhou pela imprensa e pelos livros por quase todo o século XX. Das mais de 18.000 imagens existentes no arquivo, são tantos os textos que foram vistos, reescritos, lidos e relidos pelo cronista; publicados e republicados com outros formatos, outros títulos, enfim, muitas das crônicas de Rubem Braga atravessaram a imprensa dos mais diversos rincões do Brasil. Do original às publicações há uma história a ser contada.

Algumas crônicas venceram o tempo, atravessaram os espaços. Outras seguiram no tempo, sendo publicadas num continuum, vencendo décadas, originando uma sequência, mantendo um fio condutor, alargando a história, abrindo novas janelas, fazendo o leitor quase esquecer o fato, a revelação que o cronista pretendia guardar para si num pacto solitário: “[...] fiquei algum tempo a pasmar pela madrugada, [...]; "[Não sei se ainda há mulheres assim]".

A segunda das duas crônicas é "São Paulo não mudou nada". Em relação a esta crônica o arquivo registra três publicações sendo que, em duas das versões, com dois títulos diferentes. No jornal O Estado de São Paulo, em 3/4/1987, o texto da crônica foi publicado com o título: "São Paulo e suas moradas", certamente a primeira publicação. A segunda publicação registra-se na Revista Nacional $\mathrm{n}^{\circ} .438$, de 19/04/1987. Apenas alguns dias de diferença entre as publicações o título foi modificado: de "São Paulo e suas moradas" para "São Paulo não mudou nada". Já no ano de 1988, no livro As boas coisas da vida, a crônica foi publicada como título "São Paulo e suas moradas".

Mais uma crônica e Rubem Braga parece seguir fiel às suas palavras: "[...] corrigir sempre melhora. E corrigir quer dizer uma palavra ou outra, e cortar muitas.]". Alterações textuais fazem parte da rotina do cronista. Nesta crônica, o narrador em primeira pessoa puxa o fio do contar pela memória, pensa nos tempos idos, em lembranças da juventude, recordações nem sempre tão agradáveis de relembrar. Personagens, escritores, títulos de livros vão formando um cenário onde lembranças, pessoas e lugares vão ganhando cada qual sua dimensão de fato vivido. Há fatos históricos e políticos que se misturam no contar e em outros registros. "ouvimos o discurso de Getúlio lançando o Estado novo" (p. 106), declaração feita também, em Samuel Wainer, Minha razão de viver - memórias de um repórter. Pintores, escritores, amigos que se entrelaçam a outros e mais outros cada qual com seu endereço, todos com uma particularidade. Ora ao lado de um jogo de sinuca, de um cemitério ou de uma loja de colchões.

Mas será no desfecho deste contar frouxo, suave e misturado como a memória do cronista: [um tanto arbitrária e infiel [...]" (As Boas coisas da vida, p. 106) que a crônica alcança a sua consagração: "[Lembrei-me destas e outras coisas quando um amigo há meses me explicou que aquilo ficava no Itaim Bibi]" (p. 106-107). Ali, estava o começo de tudo. O nome de uma rua, assim estranho, tinha um certo parentesco, no Bairro Itaim Bibi também morava o crítico maior da nossa literatura: "[Claro! Exclamei. Onde mais poderia morar Antonio Candido a não ser no 
Itaim Bibi...]". Mais uma vez, o narrador lança mão e tira do seu repertório dados que se cruzam no contar de forma justa: escritores amigos de sempre são citados. A crônica chega ao fim exalando humor e um certo carinho pelos personagens e pela cidade de são Paulo que tal qual o cronista: "não mudou nada"

\section{CONSIDERAÇÕES FINAIS}

Desse modo, percebe-se que a presença de Antonio Candido, nos excertos do arquivo Rubem Braga, se mistura à teorização sobre a crônica, pois afinal de contas ele é considerado um expoente no tratamento teórico desse gênero ao qual ele atribui uma identidade brasileira. De fato, ela se amealhou à escrita diária de Rubem Braga, num específico, mas mesmo permanecendo "ao rés do chão", ela não é um simulacro, é o retrato fidedigno da interface estabelecida pelo próprio cronista entre jornalismo e literatura, entre realidade cotidiana e ficção extraordinária.

A partir das contribuições que oferecem o crítico ao gênero em questão, é possível caminhar na direção da análise das formas assumidas pelo texto de uma crônica, levando-se em conta as mutações pelas quais o conteúdo narrativo passa ao longo da dinâmica temporal. Por isso, "o arquivo é uma brecha no tecido dos dias, a visão retraída de um fato inesperado" (FARGE, 2009, p. 14). Porém, quando se consegue estabelecer os nexos entre essa mobilidade criativa empreendida pelo cronista, constata-se, como afirma Farge (2009), que o arquivo está agindo como um desnudamento, pois deixa transparecer os fragmentos de verdade até então retidos.

No texto das crônicas "A mulher de aeroporto internacional" e "São Paulo não muda nunca" a função de descoberta do arquivo, como maná que se oferece ao pesquisador, retrata o pensamento do cronista ao longo de sua criação, e de purificação do seu texto. Por outro lado, revela a estratégia enigmática estabelecida pelo próprio cronista que, às vezes intuitivamente, às vezes propositadamente, produz, como na vida mostrada no jornal, um labirinto para sua criação literária. A partir do núcleo da versão tida como última o leitor-pesquisador se permite transpor os limites do imponderável e recriar a história desse texto e de seus elementos constitutivos.

\section{REFERÊNCIAS BIBLIOGRÁFICAS}

ARRIGUCCI JR., Davi. Achados e perdidos - ensaios de crítica. São Paulo: Polis, 1979.

BRAGA, Rubem. A borboleta amarela. Rio de Janeiro: Record, 1980.

BRAGA, Rubem. Melhores contos - Rubem Braga. Sel. Davi Arrigucci Jr. São Paulo: Global, 2001.

CANDIDO, Antonio. A vida ao rés do chão. In: Para gostar de ler - 5. São Paulo: Ática, 2003. p. 90-99.

CHAVES, Flávio Loureiro. Crônicas e mitos de Rubem Braga. In: Brinquedo absurdo. São Paulo: Polis, 1978.

FARGE, Arlette. O sabor do arquivo. São Paulo: EdUSP, 2009.

GRÉSILON, Almuth. Elementos de crítica genética - ler os manuscritos modernos. Porto Alegre: Editora da UFRGS, 2007. 
RICOEUR, Paul. In: Temps et récit-3. Le temps raconté. Paris: Seuil, 1983.

SAMOYAULT, Tiphanie. A intertextualidade. Tradução: Sandra Nitrini. Paris: Aderaldo \& Rothschild ; São Paulo: Hucitec, 2008. 